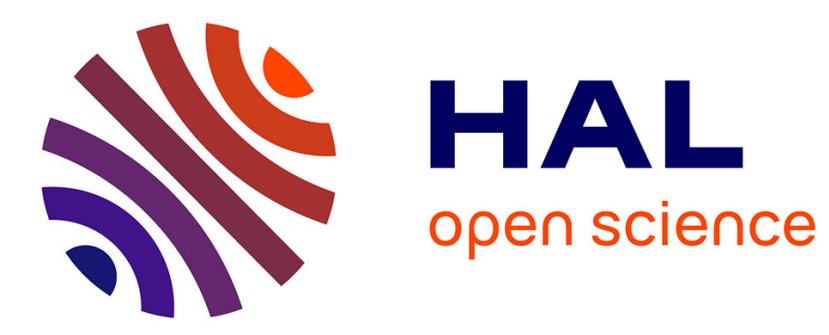

\title{
Characterization of Heavy Metal Incorporation in Calcite by XAFS Spectroscopy
}

\author{
G. Lamble, R. Reeder, P. Northrup
}

\section{To cite this version:}

G. Lamble, R. Reeder, P. Northrup. Characterization of Heavy Metal Incorporation in Calcite by XAFS Spectroscopy. Journal de Physique IV Proceedings, 1997, 7 (C2), pp.C2-793-C2-797. 10.1051/jp4:1997238 . jpa-00255317

\section{HAL Id: jpa-00255317 https://hal.science/jpa-00255317}

Submitted on 1 Jan 1997

HAL is a multi-disciplinary open access archive for the deposit and dissemination of scientific research documents, whether they are published or not. The documents may come from teaching and research institutions in France or abroad, or from public or private research centers.
L'archive ouverte pluridisciplinaire HAL, est destinée au dépôt et à la diffusion de documents scientifiques de niveau recherche, publiés ou non, émanant des établissements d'enseignement et de recherche français ou étrangers, des laboratoires publics ou privés. 


\title{
Characterization of Heavy Metal Incorporation in Calcite by XAFS Spectroscopy
}

\author{
G.M. Lamble ${ }^{* * * *}$, R.J. Reeder ${ }^{* * *}$ and P.A. Northrup ${ }^{* * *}$ \\ * Brookhaven National Laboratory, Upton, NY 11973, U.S.A. \\ ** Present address, Lawrence Berkeley National Laboratory, Berkeley, California 94720, U.S.A. \\ *** Department of Earth and Space Sciences, State University of New York, Stony Brook, NY, 11794-2100, U.S.A.
}

\begin{abstract}
Zn}$ and $\mathrm{Co} K$-edge XAFS have been analyzed for spectra obtained from synthetic calcite that incorporated trace amounts of $\mathrm{Zn}^{2+}$ and $\mathrm{Co}^{2+}$ during growth from aqueous solutions at room temperature. $\mathrm{Zn}$ and Co concentrations in the calcite ranged from 250 to $2150 \mathrm{ppm}$. Analysis of the first shells indicates that the immediate coordination of both metal ions is approximately six oxygens at $2.11-2.12 \AA$. These results are consistent with octahedral coordination at the unique $\mathrm{Ca}$ site in calcite. The observation that $\mathrm{Co}$ and $\mathrm{Zn}$ attain similar coordination in the bulk following incorporation suggests that their strongly contrasting surface site preferences are not expressed after being buried by subsequent growth layers.
\end{abstract}

\section{INTRODUCTION}

One of several important processes controlling the distribution and fate of heavy metal species dissolved in surface waters is their coprecipitation with authigenic minerals. Among these minerals, calcite $\left(\mathrm{CaCO}_{3}\right)$ has attracted much interest because of the relative ease with which it forms in a broad range of environments and its tendency to incorporate a wide variety of divalent heavy metals. Coprecipitation results in the formation of dilute solid solutions, and, in sparingly soluble phases like calcite, heavy metals that have been sequestered by coprecipitation may remain isolated from further reaction. Relative incorporation preferences of divalent metal ions in calcite have been known qualitatively for some time [1], and are generally represented by conventional distribution coefficients $[2,3]$, where $K_{\mathrm{d}}>1$ corresponds to preferential enrichment in the precipitating solid (compatible behavior) and $K_{\mathrm{d}}<1$ corresponds to discrimination by the solid (incompatible behavior). In general, differences in $K_{\mathrm{d}}$ values among metal ions of like charge are often explained on the basis of ion size relative to that of the host metal in the bulk structure ( $\mathrm{Ca}$ for calcite). However, such ion size correlations for divalent metals incorporated in calcite are inconsistent, and similarly sized metal ions may exhibit contrasting behavior $\left(e . g ., K_{\mathrm{Sr}}<1\right.$ and $K_{\mathrm{Pb}}>1$ ), suggesting that electronic configuration plays a role. Furthermore, the range of reported $K_{\mathrm{d}}$ values for an individual divalent metal ion may vary up to an order of magnitude. It has been shown that an additional factor influencing the extent of metal ion uptake is the growth rate $[4,5]$, and some of the variability in reported $K_{\mathrm{d}}$ values apparently reflects such differences.

Recent experimental work has demonstrated that the type and distribution of different surface sites on calcite play a major role in determining the relative extent of metal incorporation during growth $[6,7]$. Structurally nonequivalent growth steps on calcite (1014) faces-moving in symmetrically nonequivalent directions on the face-have been shown to incorporate metal impurities in different amounts. In some cases the incorporation difference is as large as a factor of ten. The nonequivalent growth steps occur on the vicinal faces of polygonized growth hillocks, which indicate growth occurred by the spiral mechanism. Kink sites exposed within nonequivalent growth steps have different local coordination depending on the step and kink orientation. Differences in coordination of such kink sites have been identified as the cause for different incorporation preferences for impurity metals. In situ AFM studies of layer growth on calcite (1014) surfaces also support the existence of structurally distinct growth steps and incorporation sites within them [8,9]. Consequently, surface site structure and distribution are additional important factors influencing the extent of metal uptake during crystallization.

Surface growth step/site preferences for heavy metal incorporation into calcite show some surprising inconsistencies among different ions. A notable example is the strongly contrasting behavior shown by $\mathrm{Co}^{2+}$ and $\mathrm{Zn}^{2+}$. Despite nearly identical sizes $\left(r\left(\mathrm{Co}^{2+}\right)=0.745 \AA ; r\left(\mathrm{Zn}^{2+}\right)=0.74 \AA\right)$, these metal ions show exactly opposite surface step/site preferences for incorporation. Co exhibits a preference similar to divalent ions including $\mathrm{Mg}, \mathrm{Mn}$, and $\mathrm{Fe}$, which are smaller than host $\mathrm{Ca}$. In contrast, $\mathrm{Zn}$ exhibits a preference that is similar to those shown by larger divalent ions such as $\mathrm{Sr}, \mathrm{Ba}$, and $\mathrm{Pb}$. The presence of multiple, structurally distinct surface sites on calcite, combined with observed differences in step/site selectivity, raises fundamental questions concerning the mechanism of impurity metal discrimination and incorporation. One important aspect of this relates to the local coordination of the metal impurities within the bulk crystal following incorporation. More specifically, one can ask: do Co and $\mathrm{Zn}$ have similar coordination in the bulk? The present work addresses this particular aspect using XAFS spectroscopy. The initial results reported here are limited to $\mathrm{Co}$ and $\mathrm{Zn}$ because of their strongly contrasting incorporation preferences. Future work addresses $\mathrm{Ba}$ and $\mathrm{Pb}$ incorporation.

The calcite structure has a single metal site normally occupied by $\mathrm{Ca}$. Its first coordination shell consists of six oxygens, all at $2.36 \AA$, in the form of an octahedron, only very slightly trigonally elongated. The $\mathrm{CaO}_{6}$ octahedra share corners via 
planar $\mathrm{CO}_{3}$ groups, which are arranged in layers separating cation layers along the three-fold axis. Size considerations alone would favor both $\mathrm{Co}$ and $\mathrm{Zn}$ in octahedral coordination, substituting for $\mathrm{Ca}$. And $\mathrm{CoCO}_{3}$ and $\mathrm{ZnCO}$ compounds have the calcite structure, although equilibrium solubilities of $\mathrm{CoCO}_{3}$ and $\mathrm{ZnCO}_{3}$ in calcite are extremely limited. However, because both $\mathrm{Co}$ and $\mathrm{Zn}$ exhibit compatible incorporation behavior (i.e., $K_{\mathrm{d}}>1$ ), natural calcites may contain as much as several thousand ppm Co or $\mathrm{Zn}$.

\section{METHODS}

\subsection{Coprecipitation Experiments}

Calcite single crystals (up to $500 \mu \mathrm{m}$ ) were grown from Ca- $\mathrm{NH}_{3}-\mathrm{CO}_{3}-\mathrm{Cl}$ aqueous solutions at room temperature according to the method described by Paquette and Reeder [6]. Solutions were doped with individual divalent metal species (Co or Zn), which were incorporated into the calcite during growth. Crystals were removed from growth solutions, rinsed with deionized water to remove any metals adsorbed to the surface, and dried. Concentrations and distributions of divalent metals were analyzed by synchrotron X-ray fluorescence microanalysis at NSLS (beamline X-26A) and by EPMA. Two Co-doped calcites selected for XAFS work contained 375 and $2150 \mathrm{ppm} \mathrm{Co}$, respectively. In addition two Zn-doped samples were selected, containing 250 and $1200 \mathrm{ppm} \mathrm{Zn}$, respectively. Crystals were ground in a pestle and mortar in alcohol or acetone and allowed to dry.

\subsection{Other Samples and Reference Compounds}

A natural $\mathrm{Zn}$-containing calcite from Franklin, NJ, USA, was used for comparison with the synthetic calcite. Reagent $\mathrm{ZnO}$ and natural $\mathrm{ZnCO}_{3}$ (smithsonite) from Kelly Mine, NM, USA, were used as reference compounds for $\mathrm{Zn}^{2+}$. CoO was used as a reference compound for $\mathrm{Co}^{2+}$. At the time of writing, a suitable $\mathrm{CoCO}_{3}$ sample was not yet available, and a natural Cocontaining calcite from Katanga, Zaire, was incompletely analyzed.

\subsection{XAFS Experiments and Analysis}

Co and $\mathrm{Zn} K$-edge XAFS spectra were collected at beamline X-11A of the National Synchrotron Light Source, Brookhaven National Laboratory, USA. Powder samples were pressed into aluminum sample holders, which were mounted on a cold finger cooled with liquid nitrogen. Si(111) crystals were used in the monochromator, which was calibrated using the first inflection point in edge scans of $\mathrm{Co}$ or $\mathrm{Zn}$ metal foils. The energy resolution at the edges of interest was approximately 1-1.5 eV. Higher order harmonics were rejected by slightly detuning the angle of one monochromator crystal with respect to the other until the harmonic contribution was negligible. One data set was obtained using a focusing-crystal arrangement that increased the flux at the sample [10]. Absorption measurements on the dilute heavy metal-containing calcite samples were made by monitoring the fluorescence yield above the $k$-edge of interest using a Canberra 13-element Ge solid-state detector. Spectra were obtained for reference compounds in transmission mode.

After background subtraction utilizing a modified cubic spline method, data were normalized and converted to $k$-space. Background-subtracted, normalized XAFS data were fitted in $R$-space using the program FEFFIT [11] with model calculations from FEFF6 $[12,13]$. Fitting used both the imaginary and real parts of the Fourier transforms and minimized the difference between the background-subtracted, normalized data and the model $\chi(R)$, where $\chi(R)$ is the Fourier transform calculated from $\chi(k)$ by FEFF6. $E_{0}$ was treated as a variable parameter during fitting.

\section{RESULTS AND DISCUSSION}

\subsection{Coordination of $\mathrm{Zn}$ in Calcite}

Both $\mathrm{Zn}$-doped synthetic calcite samples $(250 \mathrm{ppm}$ and $1200 \mathrm{ppm}$ ) showed essentially identical absorption spectra. In addition, these spectra are nearly identical to the natural Zn-containing calcite. Figure 1 shows the background-subtracted raw XAFS data for both synthetic calcite samples, the natural calcite, and the $\mathrm{ZnCO}_{3}$ reference compound. Although some of the features seen in the $\mathrm{Zn}$-containing calcite spectra resemble those in $\mathrm{ZnCO}_{3}$, the latter spectrum is clearly different. Figure 2 shows the corresponding Fourier transform magnitudes for the background-subtracted raw data shown in Figure 1. The similarity among the $\mathrm{Zn}$-containing calcite samples is evident, and they are distinct from $\mathrm{ZnCO}_{3}$.

Single-shell fitting of the $\mathrm{Zn}$-containing samples was chosen to be over the $R$-space range 0.8 to $2.2 \AA$ (not phase-shift corrected) and over the $k$-space range 2.0 to $12.0 \AA^{-1}$. Figure 3 is a representation in $k$-space of the first-shell contribution for the low-concentration $(250 \mathrm{ppm})$ synthetic Zn-containing calcite compared with the corresponding fit using FEFFIT. Fits for the synthetic Zn-containing calcites yielded first shells of $6.8( \pm 1)$ oxygens at $2.12( \pm 0.02) \AA$ (Debye-Waller type factor $\left.\sigma^{2}=0.003 \AA^{2}\right)$ for the lower concentration and $6.6( \pm 1)$ oxygens at $2.12( \pm 0.02) \AA\left(\sigma^{2}=0.003 \AA^{2}\right)$ for the higher concentration sample. Fitting for the natural $\mathrm{Zn}$-containing calcite gave $6.8( \pm 1)$ oxygens at $2.12( \pm 0.02) \AA\left(\sigma^{2}=0.004 \AA^{2}\right)$. These values are consistent with $\mathrm{Zn}$ in octahedral coordination. The $2.12 \AA$ distance compares well with the $\mathrm{Zn}-\mathrm{O}$ distance of $2.111 \AA$ determined for $\mathrm{ZnCO}_{3}$ by X-ray diffraction methods [14]. Multishell fits based on a model with $\mathrm{Zn}$ in the Ca position of calcite yielded good agreement with the observed spectrum; further details will be given elsewhere. 


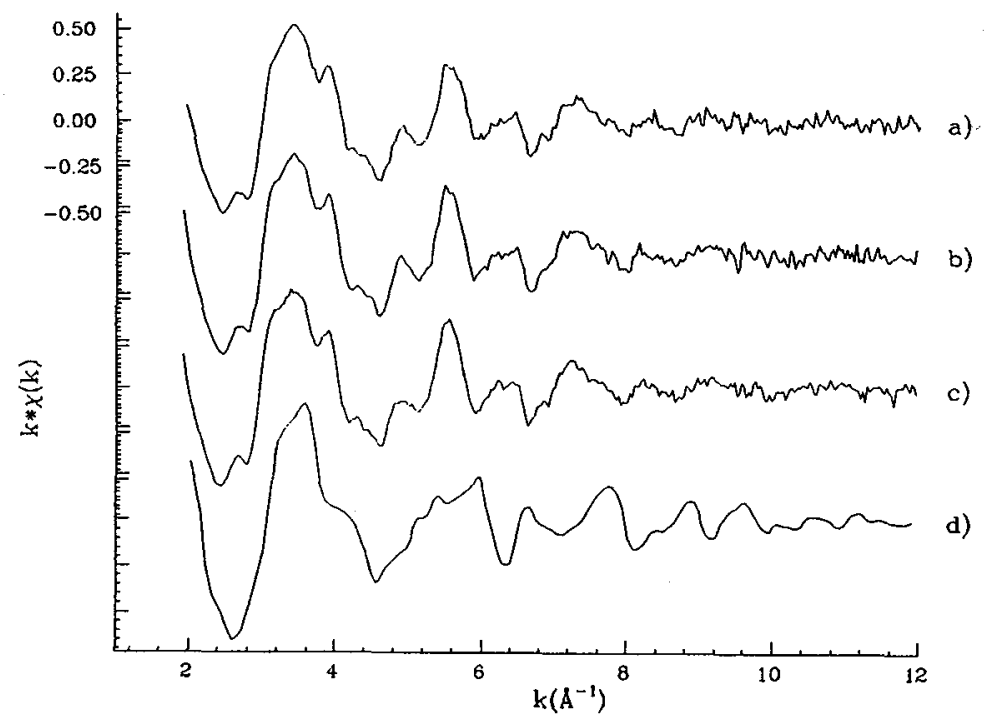

Figure 1: The $k$-weighted, background-subtracted raw XAFS data for Zn-containing samples: (a) natural Zn-containing calcite, (b) synthetic $\mathrm{Zn}$-containing calcite ( $250 \mathrm{ppm} \mathrm{Zn),} \mathrm{(c)} \mathrm{synthetic} \mathrm{Zn}$-containing calcite (1200 ppm $\mathrm{Zn}$ ), and (d) $\mathrm{ZnCO}_{3}$ reference compound.

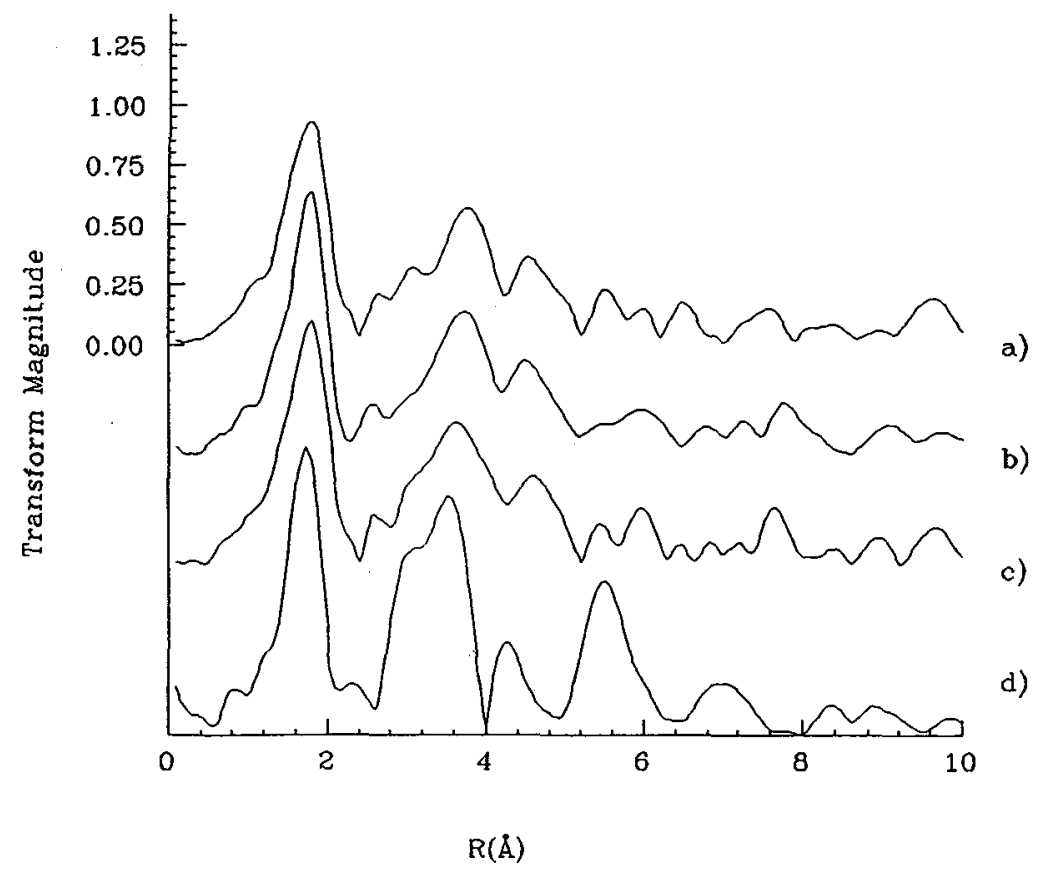

Figure 2: Fourier transform magnitudes of the background-subtracted raw data shown in Figure 1. Sample labels are given in Figure 1 caption. 


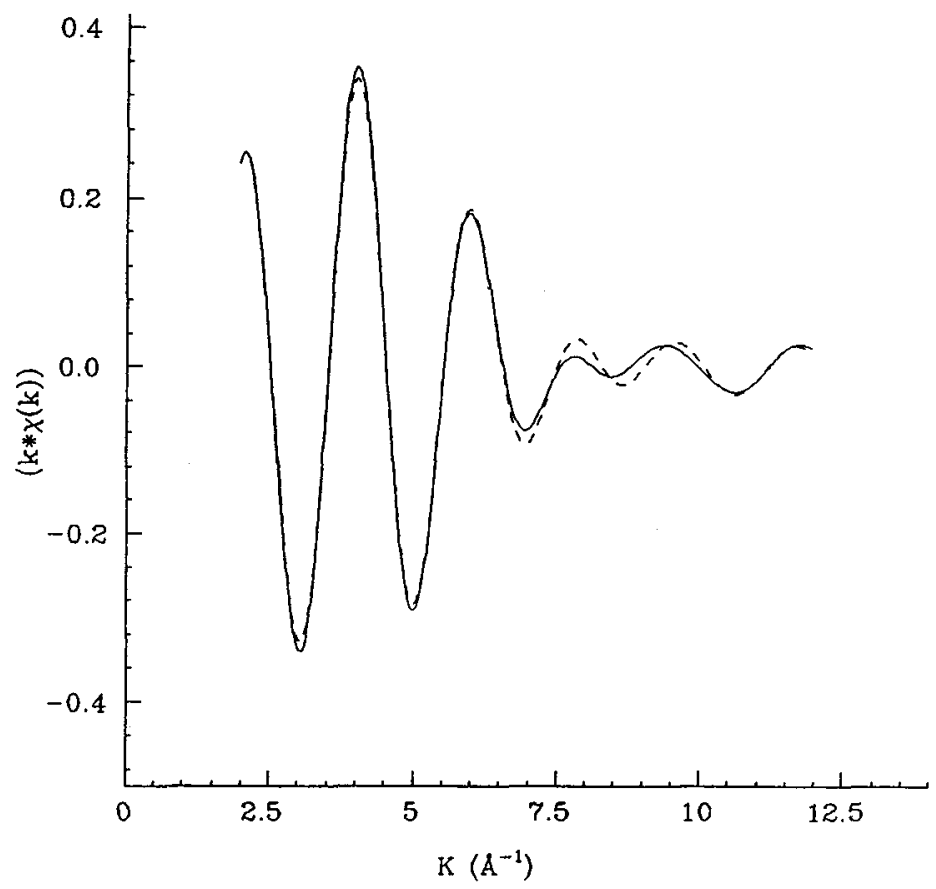

Figure 3: The $k$-space representation of the first-shell contribution of the low-concentration ( $250 \mathrm{ppm}) \mathrm{Zn}$-containing calcite (solid line) compared with that of the fit obtained in $R$-space using FEFFIT (dashed line).

\subsection{Coordination of $\mathrm{Co}$ in Calcite}

Results obtained for the synthetic Co-containing calcite samples are remarkably similar to those for the synthetic Zn-doped calcite. The two synthetic Co-doped samples produced similar spectra. A single-shell fit yielded a first shell of $5.6( \pm 1)$ oxygens at $2.11( \pm 0.02) \AA\left(\sigma^{2}=0.006 \AA^{2}\right)$. The agreement with the Co-O distance determined by X-ray diffraction, $2.110 \AA$ [15], is quite good. A multishell fit provides further detail of the local coordination and will be reported elsewhere, along with results for a natural Co-containing calcite.

\subsection{Implications}

These results confirm that both $\mathrm{Co}$ and $\mathrm{Zn}$ impurities are present in calcite in sixfold coordination with oxygen atoms, consistent with their substitution for $\mathrm{Ca}$ in the unique octahedral site. The $\mathrm{Co}-\mathrm{O}$ and $\mathrm{Zn}-\mathrm{O}$ distances determined here very closely match values found by $\mathrm{X}$-ray structure refinements for $\mathrm{CoCO}_{3}$ and $\mathrm{ZnCO}$. Although preliminary, this observation suggests that a metal ion substituting in a site normally occupied by a considerably larger ion still maintains the characteristic M-O distance observed in compounds where a site is filled entirely by that metal. The structural topology of calcite apparently does not hold the metal site open when accommodating smaller metal ions. Such behavior is important for understanding both structural and thermochemical properties of dilute solid solutions. Further examination of this behavior over a greater range of substitution is certainly warranted.

The observation that $\mathrm{Co}$ and $\mathrm{Zn}$ impurities have essentially identical coordination in the bulk calcite does little to explain their strongly contrasting preferences for different surface sites. Apparently, both ions "see" the same types of surface sites during growth, and despite opposite preferences for the differing coordination among them, their final state after incorporation is the same. It seems that upon "burial" by additional layers, any differences in surface conformation between $\mathrm{Zn}$ and Co fade or become overwhelmed once within the bulk. Similar results might be expected for other small ions. However, the question remains as to whether larger ions, such as $\mathrm{Ba}$ and $\mathrm{Pb}$, achieve similar coordination. An XAFS study of $\mathrm{Sr}$ incorporation in calcite indicates that octahedral coordination is indeed possible for that ion [16]. 


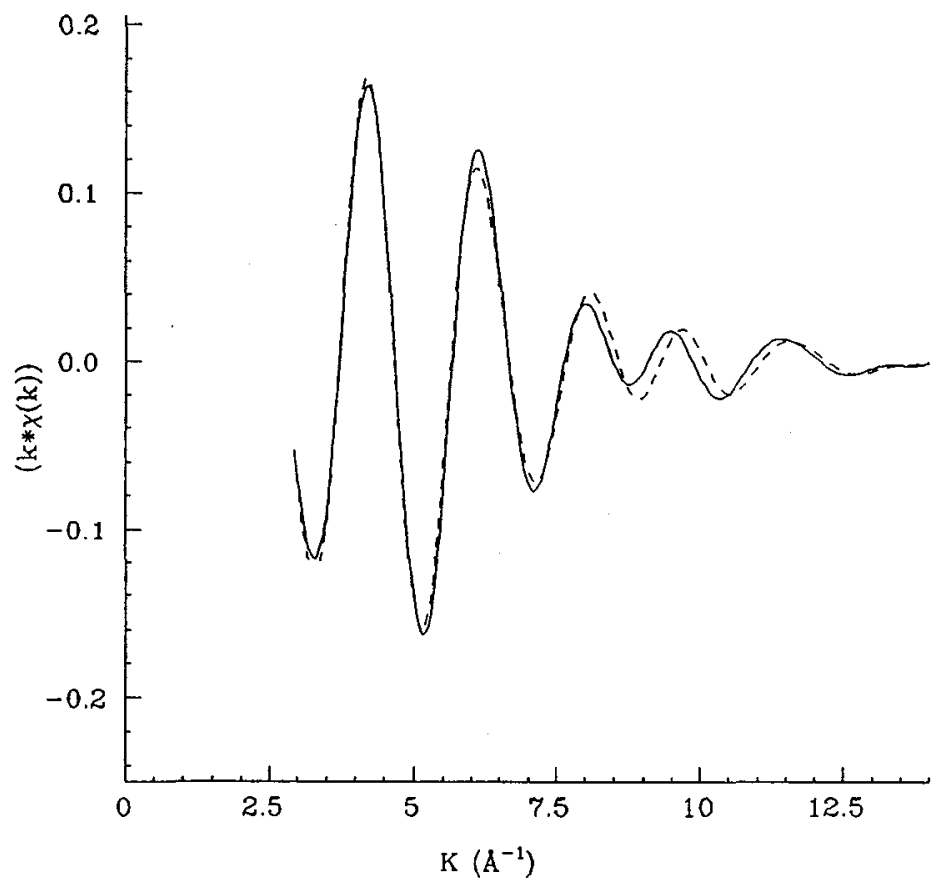

Figure 4: The $k$-space representation of the first-shell contribution of the high-concentration (2150 ppm) Co-containing calcite (solid line) compared with that of the fit obtained in $R$-space using FEFFIT (dashed line).

\section{Acknowledgments}

This work was performed at beamline X-11A at NSLS, which is supported by the US DOE Office of Basic Energy Sciences under contracts DE-AC02-76-CH00016 and DE-AS05-80-ER10742.

\section{References}

[1] Veizer, J., Carbonates: Mineralogy and Chemistry Rev. in Mineral. 11 (1983) 265-299.

[2] Morse, J. W. and Bender, M. L., Chem. Geol. 82 (1990) 265-277.

[3] Mucci, A. and Morse, J.W., Aquatic Sciences 3 (1990) 217-254.

[4] Lorens, R.B., Geochim. Cosmochim. Acta 45 (1981) 553-561.

[5] Dromgoole, E.L. and Walter, L.M., Chem. Geol. 81 (1990) 311-336.

[6] Paquette, J, and Reeder, R.J., Geochim. Cosmochim. Acta 59 (1995) 735-749.

[7] Reeder, R.J., Geochim. Cosmochim. Acta 60 (1996) 1543-1552.

[8] Gratz, A.J., Hillner, P.E., Hansma, P.K., Geochim. Cosmochim. Acta 57 (1993) 491-497.

[9] Stipp, S.L., Eggleston, C.M., Nielsen, B.S., Geochim. Cosmochim. Acta 58 (1994) 3023-3033.

[10] Lamble, G.M., and Heald, S.M., Rev. Sci. Instrum. 63 (1992) 880-884.

[11] M. Newville, Dept. of Physics, Univ, of Washington, Seattle, WA, 98195, USA; See also Stern, E.A., Physica B 208/209 (1995) 117.

[12] Rehr, J.J., Mustre de Leon, J., Zabinsky, S.I., Albers, R.C., J. Amer. Chem. Soc. 113 (1991) 5135-5140.

[13] Mustre de Leon, J., Rehr, J.J., Zabinsky, S.I., Albers, R.C., Phys. Rev. B44 (1991) 4146-4156.

[14] Effenberger, H., Mereiter, K., Zemann, J., Zeit. f. Kristallogr. 156 (1981) 233-243.

[15] Pertlik, F. Acta Cryst. C42 (1986) 4-5.

[16] Pingitore, N.E., Lytle, F.W., Davies, B.M., Eastman, M.P, Eller, P.G., Larson, E.M., Geochim. Cosmochim. Acta 56 (1992) 1531-1538. 